\title{
DEVELOPMENT OF A PROCESS MODEL FOR THE PREDICTION OF ABSORBENT DEGRADATION DURING $\mathrm{CO}_{2}$ CAPTURE
}

\author{
JILLIAN DICKINSON
}

(Received 22 May 2016; first published online 16 August 2016)

2010 Mathematics subject classification: primary 35K57; secondary 35F50, 35F60, 65M22.

Keywords and phrases: fossil fuels, $\mathrm{CO}_{2}$ capture, advection-reaction system, reaction rate kinetics, oxidative degradation of amine.

Fossil fuels are used widely for energy production and are likely to continue to play a major role world wide for many years to come. Much work has been done on the technology for capturing $\mathrm{CO}_{2}$ from gaseous industrial effluent. For large-scale applications like coal or natural gas-fired power plants, using amine solvents to capture post-combustion $\mathrm{CO}_{2}$ is the most mature $\mathrm{CO}_{2}$ capture technology. This technique can be used to retrofit existing plants by treating the flue gas after combustion.

This thesis contains a dynamic mathematical model for the absorber column that can be used to include more detailed reaction chemistry for the absorption of $\mathrm{CO}_{2}$ into an amine in the presence of $\mathrm{O}_{2}$ as it becomes available. The dynamic model is constructed from first principles and, while it is built using monoethanolamine (MEA) as the absorbent to remove $\mathrm{CO}_{2}$, it can be adjusted to cater for the removal of different industrial gases with various absorbents. This model is adapted from a system of advection-diffusion-reaction equations. The liquid phase becomes an advectionreaction system with a term for the flux of components and the gaseous phase is an advection system plus a flux term. Partial differential equations (PDEs) were used to describe the time- and space-dependent variables (concentration and temperature) of the absorber column. The mathematical problem arising from the resulting dynamic absorber model is a boundary value problem. To solve this problem, the height dimension is discretised to give an ordinary differential equation (ODE) in the time variable, at various discrete height values. The model is solved using a commercial solver, MATLAB Ode15s, when reduced to a system of ODEs by finite difference in the spatial dimension. With the two phases running countercurrently, the boundary

Thesis submitted to Monash University in December 2015; degree approved on 10 May 2016; supervisors Andrew Percy, Graeme Puxty and Vincent Verheyen.

(C) 2016 Australian Mathematical Publishing Association Inc. 0004-9727/2016 \$16.00 
conditions for the liquid are known at the top of the absorber and those for the vapour at the bottom. The boundary values for the system are given by the inlet compositions, the temperatures and the flow rates of the liquid and gas phases. It is assumed that initially the absorber column contains the flowing solvent and void vapour space and the flue gas is released into the bottom of the column.

The flux of MEA, $\mathrm{CO}_{2}, \mathrm{O}_{2}$ and $\mathrm{H}_{2} \mathrm{O}$ across the phase interface in either direction has been included and more components can be added as required. The loss of MEA through oxidative degradation has been quantified, which is currently not available using commercial packages. Reaction rate kinetics have been employed to predict the accumulation of oxidation products, which is limited by the incomplete knowledge of the dominant reactions between $\mathrm{O}_{2}$ and MEA. When research has produced more detailed information about the products formed during this oxidation, it can be inserted easily into the model.

Validation has been performed using laboratory data from CSIRO Energy Flagship, Newcastle, and data from the CSIRO PCC pilot plant at AGL Loy Yang. A limited parametric study of the impact of operating conditions on oxidation was performed.

JILLIAN DICKINSON, School of Mathematical Sciences, Monash University, Victoria 3800, Australia

e-mail: jilliand@wideband.net.au 